\title{
Adsorption Properties of Thiol-Functionalized Mesoporous Silica
}

\author{
Svetlana A. Kozlova ${ }^{a *}$, \\ Vladimir A. Parfenov a and Sergey D. Kirik \\ ${ }^{a}$ Institute of Chemistry and Chemical Technology SB RAS \\ 50/24 Akademgorodok, Krasnoyarsk, 660036, Russia \\ ${ }^{b}$ Siberian Federal University \\ 79 Svobodny, Krasnoyarsk, 660041, Russia
}

Received 12.01.2015, received in revised form 28.02.2015, accepted 14.04.2015

The synthesis and physico-chemical characteristics of thiol-functionalized mesoporous silicates MCM-41 and SBA-15 are described. The sorption properties of the materials with respect to noble metal ions, in particular palladium(II) from hydrochloric acid solutions have been studied. The materials obtained have been characterized using a complex of physical and chemical methods before and after functionalization. The evaluation of the sorption capacity of the obtained sorbents with respect to $P d(I I)$ ions has been performed. Experimental results show high sorption activity of thiol-functionalized mesoporous silica.

Keywords: mesoporous silica, MCM-41, SBA-15, thiol, functionalization, grafting, sorption, palladium.

\section{Сорбционные свойства мезопористых силикатов, функционализированных тиольными группами}

\author{
С.А. Козлова ${ }^{a}$, \\ В.А. Парфёнова ${ }^{\text {, С.Д. Кирик }}{ }^{6}$ \\ ${ }^{a}$ Институт химии и химической технологии СО РАН \\ Россия, 660036, Красноярск, Академгородок, 50/24 \\ ${ }^{6}$ Сибирский федеральный университет \\ Россия, 660041, Красноярск, пр. Свободный, 79
}

Работа посвящена синтезу и исследованию физико-химических характеристик функииональных сорбентов на основе мезопористых мезоструктурированных силикатов типа MCM-41 и SBA15 с привитыми тиольными группами. Изучены сорбичонные свойства полученных материалов по отношению к ионам благородных металлов, в частности палладия(II), из солянокислых

(C) Siberian Federal University. All rights reserved

* Corresponding author E-mail address: sakozlova@gmail.com 
растворов. Полученные материаль охарактеризованы комплексом физико-химических методов до и после функиионализации. Проведена оценка сорбиионной способности полученных материалов по отношению к ионам Pd(II). Экспериментальные результаты свидетельствуют о высокой сорбционной активности функиионализированных мезопористых силикатов.

Ключевые слова: мезопористый кремнезём, MCM-41, SBA-15, тиольные группы, функиионализация, прививка, сорбция, палладий.

\section{Введение}

Открытые в начале 90-х гг. ХХ в. мезоструктурированные мезопористые силикатные материалы (MMM) $[1,2]$ по-прежнему представляют огромный интерес для исследователей. Для указанных материалов характерно кристаллографически регулярное строение, высокая удельная поверхность, достигающая 1000 м²/г и выше, а также постоянный размер пор, лежащий в нанометровом диапазоне. Все эти характеристики являются крайне востребованными в случаях, когда химические процессы протекают на поверхности или в ограниченном объёме. А наличие силанольных групп на поверхности силикатов может обеспечивать ковалентное закрепление разнообразных органических функциональных молекул.

В настоящее время существует значительное многообразие функциональных прививок, выбор которых зависит от поставленных задач. Сера относится к наиболее сильным лигандам для переходных металлов нижней части Периодической системы химических элементов им. Д.И. Менделеева. Она вытесняет из координационной сферы галогениды, аминогруппу и многие другие функциональные группы. Не случайно многие металлы в природе накапливаются в виде сульфидных руд. В химии поверхностных соединений сера в состоянии $\mathrm{S}^{2-}$ может быть введена в виде органического тиоэфира (сульфидной группы) R-S-R' [3] или тиольной группы R-SH [4]. Модификатор, содержащий тиольную группу, является одним из наиболее простых и доступных органических алкоксисиланов. С его помощью можно проводить функционализацию силикатной матрицы для последующего изучения сорбции металлов из растворов.

Канг с соавторами [4] сообщили результаты прививки 3-меркаптопропилтриметоксисилана (MPTMS) на SBA-15 и исследования сорбентов на его основе. В результате прививки тиольной группы площадь поверхности силиката снизилась с 721 до 437 м²/г. Плотность прививки SH-групп составила 1,01 ммоль/г. Авторы отмечают интересный факт: MPTMS реагирует с поверхностью посредством двухстадийной реакции, что уменьшает плотность в процессе функционализации. Исходя из предположения, что на плоскую поверхность может поместиться 5 тиольных молекул/нм² (при полном покрытии поверхности), количество полученных привитых SH-групп составляет только 20 \% (1,01 ммоль/г) от возможного, при этом пространство, занимаемое тиольной группой, составляет $\sim$ нм²$^{2}$. Сорбцию проводили во фталатном буфере (pH 4,01) в течение 12 ч при $22{ }^{\circ} \mathrm{C}$ с перемешиванием [4]. Полученные максимальные сорбционные ёмкости (CE) по $\mathrm{Pt}^{2+}$ и $\mathrm{Pd}^{2+}$ для Thio-SBA-15 сравнимы с CE полимерных сорбентов [5-7]. Ёмкости по $\mathrm{Pt}^{2+}$ и $\mathrm{Pd}^{2+}$ составляют 1,1 и 1,6 ммоль/г, коэффициенты распределения $(\mathrm{Kd})-4 \cdot 10^{4}$ и $1 \cdot 10^{6}$ мл/г соответственно. Доступ ионов $\mathrm{Pt}^{2+}$ открыт ко всем комплексообразующим тиольным группам в материале Thio-SBA-15 (т.е. $\mathrm{Pt}^{2+} / \mathrm{S}=1.0$ ). В случае адсорбции $\mathrm{Pd}^{2+}$ тиольные функциональные группы способны связывать значительное количество ионов $\mathrm{Pd}^{2+}$ по сравнению с плотностью функциональных групп (т.е. $\left.\mathrm{Pd}^{2+} / \mathrm{S}=1,5\right)$. Различие в значениях максимальной $\mathrm{CE}$

$$
-495-
$$


материала для платины и палладия авторы [4] относят к разнице ионных радиусов для $\mathrm{Pt}^{2+}$ и $\mathrm{Pd}^{2+}$.

Несмотря на огромный рост публикаций, касающийся синтеза сорбентов на основе мезопористых силикатов, в литературе сравнительно мало работ о решении проблем извлечения и/ или разделения ионов металлов платиновой группы (МПГ) с использованием функционализированных мезопористых кремнезёмов. Экспериментальному исследованию синтеза и сорбционных возможностей мезопористых мезоструктурированных силикатов относительно МПГ посвящена данная работа.

\section{Экспериментальная часть}

Синтез силикатных матриц и их функичинализация

Используемые реактивы: тетраэтоксисилан (TEOS): $\mathrm{Si}_{2}\left(\mathrm{C}_{2} \mathrm{H}_{5} \mathrm{O}\right)_{4}$, ч.д.а., ТУ 6-09-3687-74; цетилтриметиламмония бромид (CTABr): $\mathrm{C}_{16} \mathrm{H}_{33}\left(\mathrm{CH}_{3} \mathrm{O}\right)_{3} \mathrm{NBr}$, Aldrich (Cat.:85.582-0); водный раствор аммиака, $\rho=0,905 г / \mathrm{cm}^{3}$, ч.д.а.; этанол-ректификат (EtOH), 96 \% масс; триблоксополимер

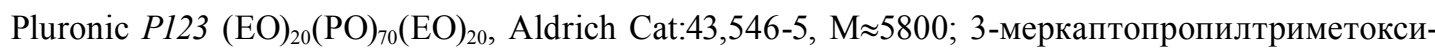
силан (MPTMS): $\mathrm{C}_{6} \mathrm{H}_{16} \mathrm{O}_{3} \mathrm{SSi}$ (Aldrich, Cat.: 175617); толуол: $\mathrm{C}_{6} \mathrm{H}_{5} \mathrm{CH}_{3}$, х.ч.; $\mathrm{HCl}$, х.ч.

Синтез МСМ-41. Синтез МСМ-41 проводили в спиртово-аммиачной среде с мольным соотношением реагентов [8]

$$
1 \text { TEOS : 0,2 CTABr : } 22 \mathrm{NH}_{3}: 52 \mathrm{EtOH}: 475 \mathrm{H}_{2} \mathrm{O} \text {. }
$$

3,98 г СТАВr растворяли в водно-спиртовом растворе (400 мл $\mathrm{H}_{2} \mathrm{O}$ и 168 мл EtOH) при комнатной температуре при перемешивании. По завершении растворения добавляли 89 мл аммиака (pH 12,5). Затем в образовавшийся раствор из делительной воронки очень медленно добавляли 11,5 г TEOS при энергичном перемешивании на магнитной мешалке. В процессе синтеза полученный раствор перемешивался в течение 2 ч. Далее реакционную смесь переносили в автоклав для проведения гидротермальной обработки (ГТО) при температуре $120^{\circ} \mathrm{C}$ в течение двух часов.

Полученный осадок фильтровали, промывали водой, сушили на воздухе при комнатной температуре. Для удаления органической составляющей материал прокаливали в муфельной печи «Heraeus» D-63450 (Германия) на воздухе. Температуру в печи поднимали плавно до $550{ }^{\circ} \mathrm{C}$ со скоростью $3{ }^{\circ} \mathrm{C} /$ мин и выдерживали образцы в печи ещё 3 ч.

Синтез SBA-15. Синтез SBA-15 выполняли по методике, описанной Zhaо с соавторами [9]. В растворе, содержащем 45 мл воды и 180 г $2 \mathrm{M} \mathrm{HCl}$, растворяли 6 г P123 при интенсивном перемешивании на магнитной мешалке на водяной бане при температуре $50{ }^{\circ} \mathrm{C}$. Процесс полного растворения протекает за 3-4 ч. Снижая температуру реакционной смеси до $40{ }^{\circ} \mathrm{C}$, добавляли 12 г TEOS. Смесь оставляли при интенсивном перемешивании на 24 ч. Далее раствор с образовавшейся взвесью выдерживали в сушильном шкафу в течение 48 ч при температуре $80{ }^{\circ} \mathrm{C}$. Твердый осадок фильтровали, промывали водой, сушили на воздухе при комнатной температуре, затем прокаливали при $550{ }^{\circ} \mathrm{C}$ в течение 3 ч.

Функционализация мезосиликатов тиольными группами. В круглодонную колбу помещали 1,0 г носителя, добавляли 20 мл обезвоженного толуола и несколько минут диспергировали носитель в растворителе. Затем в реакционную смесь вводили 1,5 г 3-меркаптопро-

$$
\text { - } 496 \text { - }
$$




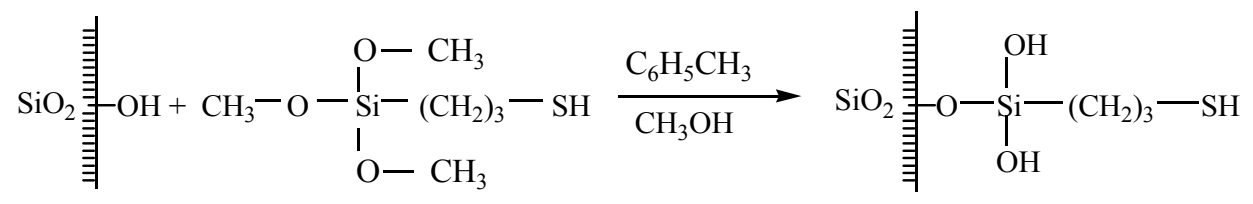

Рис. 1. Схема прививки MPTMS к носителю $\mathrm{SiO}_{2}$

пилтриметоксисилана (MPTMS) (рис. 1). Полученную суспензию перемешивали на магнитной мешалке в атмосфере, исключающей влажность воздуха при температуре кипения в течение 24 ч. Полученный продукт промывали небольшими порциями толуолом, горячим этиловым спиртом и высушивали на воздухе при комнатной температуре.

\section{Характеризация сорбентов}

Для исследования исходных и функционализированных образцов мезосиликатов применяли комплекс физико-химических методов. Съёмку рентгенограмм проводили на дифрактометре X'PertPRO (PANanalytical) с использованием $\mathrm{Cu}_{\text {ка }}$-излучения в угловом интервале $2 \theta$ $0,40-7,04^{\circ}$ с шагом $0,026^{\circ}$ и временем накопления 120 с в каждой точке.

Для подтверждения упорядоченности структуры выполняли съёмку функционализированных образцов на просвечивающем электронном микроскопе JEM-2100 (JEOL). Адсорбционные измерения поверхности проводили на приборе «ASAP 2420» (Micromeritics, USA) при T=98 К в интервале относительных давлений (p/p p 0,06-0,99 с шагом 0,015. Съёмку ИК-спектров осуществляли на оборудовании «Tensor 27» (Bruker) в интервале 400-4000 см-1. Таблетки готовили с использованием $\mathrm{KBr}$. Массовое соотношение образец: $\mathrm{KBr}=1: 400$. Навеска образца составляла 1,5 мг. Общее содержание функциональной прививки на модифицированных образцах определяли на термическом анализаторе SDT Q600 (TA Instruments, США). Вес образцов около 5 мг, интервал съёмки $40-900{ }^{\circ} \mathrm{C}$, скорость нагрева $20^{\circ} \mathrm{C} /$ мин.

Содержание различных элементов (в том числе палладия) в твердых пробах определяли двумя методами: 1) CHNS-анализ на элементном анализаторе CHNS/O FlashEA 1112 (ThermoQuest, Италия); вес образцов был около 5 мг 2) рентгеновская флуоресцентная спектроскопия (РФС) на спектрометре «Axios Advanced» (PANalytical, Нидерланды). Для определения содержания палладия(II) в растворах после сорбции анализировали отработанные растворы на фотоэлектроколориметре КФК-3 по методике [10] с образованием комплекса с тиомочевиной.

Для обнаружения способа взаимодействия палладия с функционализированной поверхностью мезосиликатов проводили измерения образцов на фотоэлектронном спектрометре SPECS (SPECS GmbH, Германия), укомплектованном энергоанализатором электронов PHOIBOS HSA3500 150 MCD9 при возбуждении излучением $\mathrm{Mg}$ К $\alpha$ рентгеновской трубки. Энергия пропускания энергоанализатора составляла 20 эВ при регистрации обзорных спектров, 8 эВ для узких сканов. Порошкообразные образцы закрепляли на двусторонней липкой углеродной ленте. Вакуум в аналитической камере спектрометра был не менее $1 \cdot 10^{-9}$ мБар. Травление ионами аргона для очистки поверхности и удаления поверхностного слоя проводили при энергии, ускоряющем напряжении 2,5 кВ и ионном токе 15 мкА, как правило, в течение 5 мин, что соответствует удалению слоя 0,5-1 нм. Поправку на электростатическую подзарядку образцов

$$
-497-
$$


вводили с учетом положения линии $\mathrm{C} 1 \mathrm{~s}$ (энергия связи принималась равной 285,0 эВ) углеводородов. Относительные концентрации элементов определяли по обзорным спектрам; для записи и обработки спектров использовали пакеты программ SpecsLab и CasaXPS. При определении относительных концентраций элементов и при разложении линий вычитали нелинейный фон по Ширли, принимая форму линий гауссовско-лоренцевской (50 \%).

Изучение сорбции палладия (II). Модельные растворы хлоридных комплексов палладия (II) готовили термическим разложением комплекса транс-диаминдихлорид палладия(II) (trans$\left.\left[\mathrm{Pd}\left(\mathrm{NH}_{3}\right)_{2} \mathrm{Cl}_{2}\right]\right)$ до металлического палладия при $800^{\circ} \mathrm{C}$. Затем поверхность дисперсного палладия восстанавливали муравьиной кислотой и металл растворяли в царской водке по реакции

$$
\mathrm{Pd}+4 \mathrm{HCl}+2 \mathrm{HNO}_{3} \rightarrow \mathrm{H}_{2}\left[\mathrm{PdCl}_{4}\right]+2 \mathrm{NO}_{2}+2 \mathrm{H}_{2} \mathrm{O} .
$$

Полученный раствор трёхкратно упаривали с $\mathrm{HCl}$ для полного вытеснения из системы $\mathrm{HNO}_{3}$. Полученный порошок $\mathrm{PdCl}_{2}$ растворяли в избытке $\mathrm{HCl}$ с образованием комплекса $\mathrm{H}_{2}\left[\mathrm{PdCl}_{4}\right]$, избыток $\mathrm{HCl}$ применялся для создания необходимой кислотности.

Сорбцию палладия(II) проводили из хлоридного раствора в статическом режиме. Навеску сорбента 50 мг помещали в коническую колбу на 50 мл с резиновой пробкой, добавляли 10 мл исследуемого раствора палладия. Время контакта раствора и навески сорбента составляло 24 ч при постоянном перемешивании на шейкере со скоростью 170 об/мин. После отделения сорбента (фильтр «синяя лента») сухой остаток промывали дистиллированной водой и сушили на воздухе при $80{ }^{\circ} \mathrm{C}$ в сушильном шкафу. Далее количество палладия в фильтрате определяли фотометрическим способом, в сухом остатке - методом РФС.

Десорбцию выполняли в статическом режиме при комнатной температуре. Сорбент после сорбции (высушенный и взвешенный) помещали в коническую колбу с пробкой, заливали 3 мл 5\%-ного раствора тиомочевины в $1 \mathrm{M} \mathrm{HCl}$ и встряхивали в течение 5-10 мин. По завершении десорбции раствор отделяли от сорбента и определяли содержание палладия в растворе фотометрическим методом или рентгенофлуоресцентным анализом.

\section{Результаты и обсуждение}

\section{Результаты анализа сорбентов}

Рентгенографическое исследование показало, что после функционализации значение параметра решётки (a) практически сохраняется: для МСМ-41 лежит в пределах 42-44 $⿱$ А́, для SBA-15 - 102-109 А́ (табл. 1). Материалы обладают высокой степенью гексагональной упорядоченности, что подтверждается как рентгенографическим анализом (рис. 2), так и просвечивающей электронной микроскопией (рис. 3). В результате прививки на дифрактограммах наблюдается уменьшение интенсивности второго и третьего рефлексов. Последнее является доказательством заполнения пор, а не межкристаллического пространства [11, 12].

На ИК-спектрах (рис. 4) рассматриваемых образцов в области 400-1200 см-1 наблюдаются три полосы, отвечающие колебаниям $\mathrm{Si}-\mathrm{O}-\mathrm{Si}$ связей в тетраэдре $\mathrm{SiO}_{4}$. Широкая п.п. с максимумом 3440-3480 см-1 и менее интенсивные полосы с максимумами 1600-1640 и 2344-2368 см


сывается изолированному типу силанольных групп. В процессе модифицирования изменения претерпевает область 1400-1500 см-1, отвечающая валентным С-С колебаниям в алканах, и 
Таблица 1. Некоторые характеристики тиольных сорбентов, полученных одностадийной прививкой. $\mathrm{m}_{\text {сорб. }}=50 \mathrm{мг,} \mathrm{V}_{\mathrm{p}-\mathrm{pa}}=10 \mathrm{мл,} \mathrm{C}\left(\mathrm{Pd}^{2+}\right)=3$ мМ. Время сорбции 24 ч

\begin{tabular}{|c|c|c|c|c|c|c|c|c|}
\hline $\begin{array}{c}\text { № } \\
\text { сорбента }\end{array}$ & $\begin{array}{l}\text { Матрица/ } \\
\text { Сорбент }\end{array}$ & $\begin{array}{c}\text { Параметр } \\
\text { решётки, } a\end{array}$ & $\begin{array}{c}\mathrm{S}_{\text {уд }}(\mathrm{BET}), \\
\mathrm{M}^{2} / \Gamma\end{array}$ & $\mathrm{V}_{\text {пор }}, \mathrm{cm}^{3} / \Gamma$ & $\begin{array}{c}D_{\text {пор }} \\
(4 \mathrm{~V} / \mathrm{A}), \AA\end{array}$ & $\begin{array}{c}\text { Плотность } \\
\text { прививки, } \\
\text { ммоль/г }\end{array}$ & $\begin{array}{c}\text { CE по } \mathrm{Pd}^{2+}, \\
\text { ммоль } / \Gamma\end{array}$ & $\mathrm{S} / \mathrm{Pd}$ \\
\hline & MCM-41 & 43,46 & 246 & 0,3 & 41,5 & & & \\
\hline \multirow[t]{2}{*}{1} & $\mathrm{M} 1 \mathrm{M}$ & - & 403 & 0,2 & 21,6 & 1,0 & 0,6 & 1,7 \\
\hline & MCM-41 & 43,91 & 1048 & 0,9 & 32,7 & & & \\
\hline \multirow[t]{2}{*}{2} & $\mathrm{M} 2 \mathrm{M}$ & 44,74 & 875 & 0,5 & 23,3 & 1,1 & 0,5 & 2,3 \\
\hline & SBA-15 & 109,24 & 587 & 1,0 & 66,9 & & & \\
\hline \multirow[t]{2}{*}{3} & M3S & 107,28 & 425 & 0,7 & 67,2 & 1,1 & 0,5 & 2,4 \\
\hline & MCM-41 & 42,79 & 572 & 0,6 & 31,6 & & & \\
\hline \multirow[t]{2}{*}{4} & M4M & 43,68 & 606 & 0,5 & 30,8 & 1,3 & 0,5 & 2,5 \\
\hline & MCM-41 & 42,00 & 1032 & 0,8 & 28,9 & & & \\
\hline \multirow[t]{2}{*}{5} & M5M & 42,70 & 874 & 0,5 & 21,5 & 1,1 & 1,0 & 1,1 \\
\hline & MCM-41 & 43,55 & 971 & 0,7 & 30,6 & & & \\
\hline \multirow[t]{2}{*}{6} & M6M & 43,46 & 780 & 0,4 & 21,3 & 1,3 & 1,1 & 1,2 \\
\hline & SBA-15 & 105,35 & 550 & 0,8 & 59,4 & & & \\
\hline \multirow[t]{2}{*}{7} & ${\mathrm{M} 7 \mathrm{~S}^{1}}^{1}$ & 102,85 & 330 & 0,5 & 56,8 & 1,5 & 1,7 & 0,9 \\
\hline & MCM-41 & 42,75 & 572 & 0,5 & 35,8 & & & \\
\hline \multirow[t]{2}{*}{8} & $\mathrm{M}^{2} \mathrm{M}^{1}$ & 43,80 & 653 & 0,4 & 25,5 & 1,8 & 1,6 & 1,1 \\
\hline & SBA-15 & 106,45 & 686 & 0,8 & 46,9 & & & \\
\hline \multirow[t]{2}{*}{9} & $\mathrm{M}^{1} \mathrm{~S}^{1}$ & 103,45 & - & - & - & 1,3 & 1,5 & 0,9 \\
\hline & MCM-41 & 42,15 & 1046 & 0,8 & 30,5 & & & \\
\hline 10 & $\mathrm{M}^{10 \mathrm{M}^{1}}$ & 42,90 & - & - & - & 1,5 & 1,4 & 1,1 \\
\hline
\end{tabular}

${ }^{1}$ Сорбент получен в две стадии: 1 - пропитка в избытке модификатора при комнатной температуре, 2 - нагрев с небольшим количеством растворителя при перемешивании.

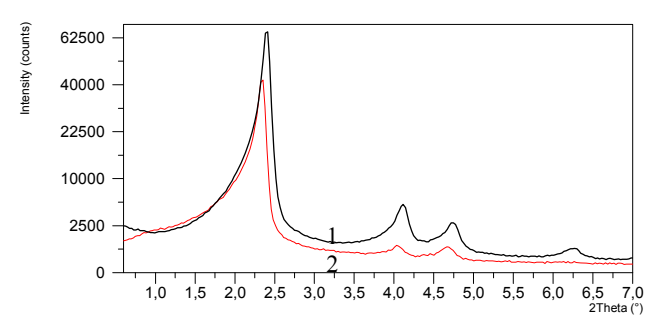

a

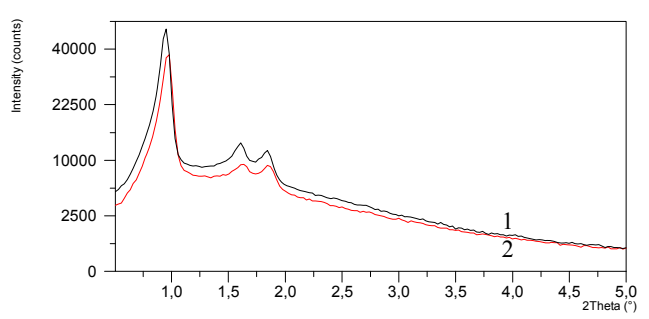

6

Рис. 2. Рентгенограммы исходных силикатов (1) и сорбентов (2) для: а - MCM-41; б - SBA-15

2930-2960 см ${ }^{-1}$, которую относят к С-Н-колебаниям, а также крайне слабо выраженная область 2550-2600 см ${ }^{-1}$, отвечающая колебаниям SH-групп. По исчезновению или ослаблению полосы $3745 \mathrm{~cm}^{-1}$ можно судить о полноте протекания реакции на поверхности [13].

На термограмме (рис. 5) можно выделить два основных процесса. В температурном интервале 80-200 ${ }^{\circ} \mathrm{C}$ происходит потеря адсорбированной воды и, возможно, молекул органических 

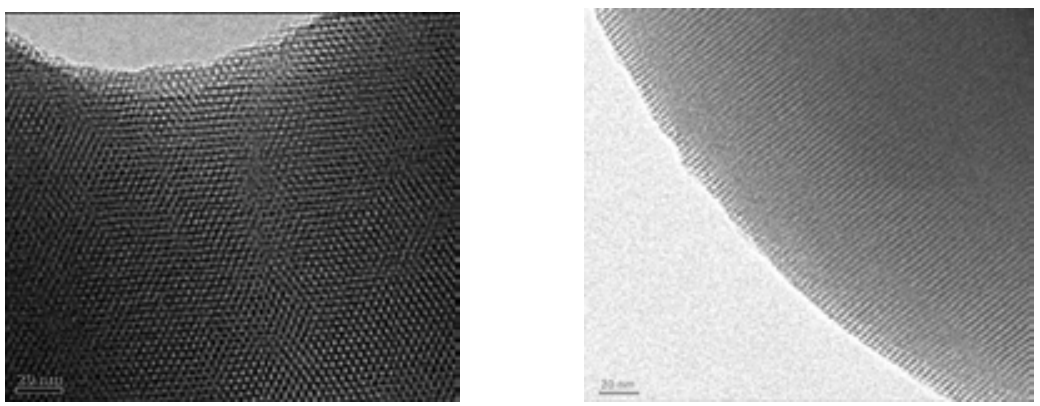

Рис. 3. Электронные микрофотографии ПЭМ тиольного сорбента М6М

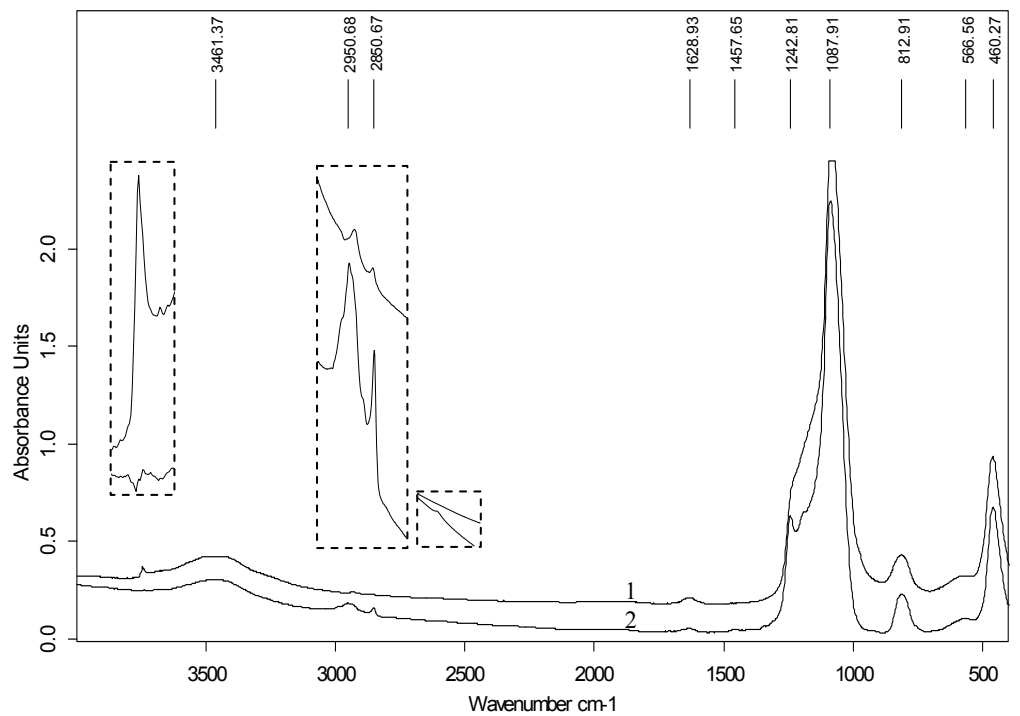

Рис. 4. ИК-спектры образцов: 1 - исходный МСМ-41; 2 - сорбент М2М

растворителей (толуол, этанол), применявшихся при синтезе. Далее, начиная с температуры $300{ }^{\circ} \mathrm{C}$, наблюдается экзотермический процесс окисления органической компоненты. Поскольку вынос продуктов окисления из пор сопряжен с диффузионными затруднениями, разложение растянуто во времени. Термические данные позволяют оценить количество привитого материала: весовая доля прививки для тиольных сорбентов составляет 15-20 \%.

На термограмме (рис. 5) можно выделить два основных процесса. В температурном интервале 80-200 ${ }^{\circ} \mathrm{C}$ происходит потеря адсорбированной воды и, возможно, молекул органических растворителей (толуол, этанол), применявшихся при синтезе. Далее, начиная с температуры $300{ }^{\circ} \mathrm{C}$, наблюдается экзотермический процесс окисления органической компоненты. Поскольку вынос продуктов окисления из пор сопряжен с диффузионными затруднениями, разложение растянуто во времени. Термические данные позволяют оценить количество привитого материала: весовая доля прививки для тиольных сорбентов составляет 15-20 \%.

По данным РФС образцы на основе MCM-41 и SBA-15 имеют в среднем плотность прививки 1,3 и 1,1 ммоль/г (в двухстадийной прививке до 1,5-1,7 ммоль/г) соответственно. При из- 




Рис. 5. Термограмма М4М. Первая стадия (до $\left.180^{\circ} \mathrm{C}\right)$ - отлёт физически адсорбированной воды составляет $3,5 \%$; вторая стадия (выше $300^{\circ} \mathrm{C}$ ) - окисление органической компоненты - 18,5 \%



Рис. 6. Пример изотермы газовой адсорбции исходного MCM-41 (1) и сорбента M3S (2) и распределение пор по размерам для адсорбционной кривой: a-MCM-41; б - M3S

менении способа удаления ПАВ из силикатной матрицы (замена отжига на экстрагирование) наблюдается увеличение плотности прививки. К увеличению плотности также приводит активация поверхности силиката при кипячении его в воде, как следствие, рост числа силанольных групп на поверхности [16]. 


\section{Результаты сорбции палладия(II)}

Из представленных в табл. 1 данных видно, что существует различие между плотностью прививки и ёмкостью сорбента. Высокая гидрофобность поверхности ММС и самих меркаптогрупп, по-видимому, снижает поверхность, участвующую в сорбции ионов металлов. Кроме того, имеет место неравномерность распределения прививки, приводящая к образованию гидрофобных «островков» и «пробок». Такие явления влияют на стабильность результатов по сорбции металлов. Подтверждением того служит множество несогласующихся результатов и в литературе [13, 17].

Изотерма сорбции. Из формы изотермы (рис. 7) сорбции палладия(II) видно, что комплексообразование палладия(II) с меркаптогруппами сорбента квазинеобратимо и сорбенты характеризуются очень высоким сродством к иону палладия(II). Уже при концентрации менее 3 мМ достигается приблизительно 80-90 \% от величины полной СЕ сорбента.

Максимальные измеренные сорбционные ёмкости для ММС по отношению к ионам Pd(II) достигают значений 0,9-1,1 ммоль/г, для синтезированных двухстадийной прививкой -до 1,51,7 ммоль/г (рис. 7). Несмотря на разницу в текстурных параметрах, очевидного различия в скорости сорбции функциональными материалами MCM-41 и SBA-15 не обнаружено.

Кинетика сорбции. Изучение сорбционной ёмкости от времени проводили при комнатной температуре. Исходная концентрация палладия (II) составляла в среднем 3,5 мM/л.

Образцы M5M, M6S, содержащие наибольшее количество привитых SH-групп $(1,1$ ммоль/г), для одностадийной прививки имеют максимальную скорость сорбции и быстрое установление равновесия. Образцы М1M - М4М показывают меньшую скорость, для насыщения раствором требуется более до 24 ч, при этом они имеют наименьшую сорбционную ёмкость 0,5-0,6 ммоль/г (табл. 1). Несмотря на большие размеры пор в материале SBA-15, особого роста скорости сорбции не отмечено. Очевидно, что диффузионные затруднения в обоих случаях отсутствуют. Там, где скорость мала, вероятно, имеются диффузионные затруднения (возможно, пробки в порах), связанные с неучтёнными особенностями синтеза.

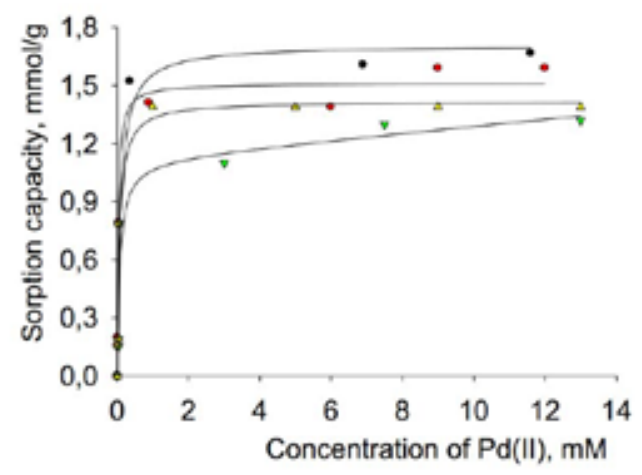

a



б

Рис. 7. Кривые сорбции палладия (II) MMC, полученных двухстадийной прививкой, $\mathrm{C}_{\mathrm{HCl}}=1 \mathrm{M}$ : a - изотермы сорбции; б - зависимость СЕ от времени, $\mathrm{C}_{\mathrm{Pd}}=3,5 \mathrm{MM}$ 
Влияние этилового спирта и уксусной кислоты на сорбцию. Как упоминалось выше, привитые на поверхность силиката меркаптогруппы гидрофобны по своей природе. Это свойство увеличивает поверхностное натяжение при контакте раствора и поверхности сорбента и, вероятно, препятствует вхождению раствора в поры. Для уменьшения поверхностного натяжения в раствор добавляли этиловый спирт $(\boldsymbol{E} \boldsymbol{t})$ или уксусную кислоту $(\boldsymbol{A c})$ в количестве 10 и 50 об. \% относительно общего количества раствора. Амфифильные молекулы спирта, ориентируясь органическими «хвостами» к поверхности, а полярными группами к раствору, как полагалось, должны уменьшать отталкивание двух сред. Однако полученные результаты показали, что введение спирта/уксусной кислоты в раствор не приводит к повышению сорбционной ёмкости, а в некоторых случаях даже снижает её (рис. 8). Это свидетельствует о том, что резерв для увеличения контакта с поверхностью отсутствует. Некоторое снижение ёмкости можно объяснить непосредственной адсорбцией спирта на SH-группы сорбента и блокировкой доступа ионов палладия к поверхности материала. Можно также допустить, что сольватная оболочка иона $\left[\mathrm{PdCl}_{4}\right]^{2-}$ дополняется молекулами спирта и уменьшает его способность к взаимодействию с функциональными группами сорбента.

Импрегнирование сорбата в вакууме при сорбции Pd(II). Предполагается, что создание вакуума в течение 15 мин в процессе сорбции освобождает поры от воздуха, благодаря чему проникновение раствора палладия (II) внутрь пор становится легче. Вакуум создавали с помощью водоструйного насоса. Интересно отметить, что содержание серы и хлора в результате создания вакуума практически не меняется, а содержание палладия растёт примерно на 20 \% (рис. 9).

Комплексообразование Pd(II) на поверхности. Для установления особенностей комплексообразования на поверхности сорбента были сняты фотоэлектронные спектры методом РФЭС. На рис. 10 приведены спектры РФЭС исходного привитого образца «М5М», в состоянии сорбции ртути «M5M_Pd» и после травления аргоном $(2,5 \mathrm{kV}, 15 \mathrm{mkA})$ «M5M_Pd_Ar».

Из данных рис. 10в видно, что после сорбции палладия энергия связи серы снижается (с 163,7 до 163,3 эВ), что можно объяснить образованием связывания Pd-S, однако ЭС 163,3 эВ



Рис. 8. Результаты сорбции $\mathrm{Pd}(\mathrm{II})$ на сорбенте M2M (табл. 1) в присутствии различных количеств этилового спирта/уксусной кислоты 


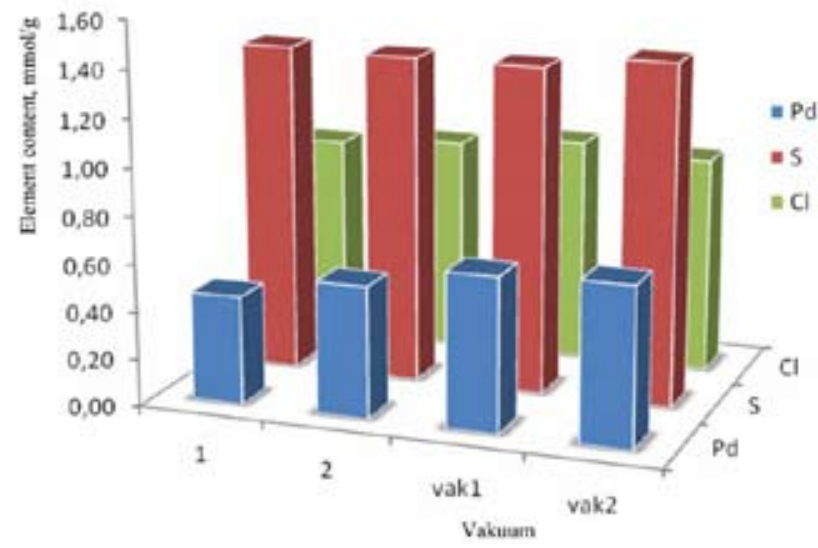

Рис. 9. Результаты сорбции $\mathrm{Pd}(\mathrm{II})$ в вакууме на примере сорбента M2M

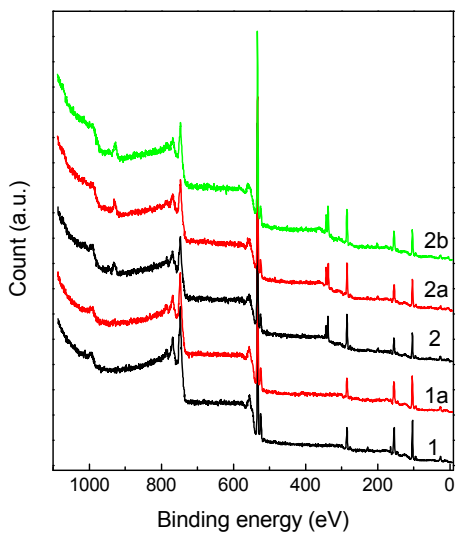

a

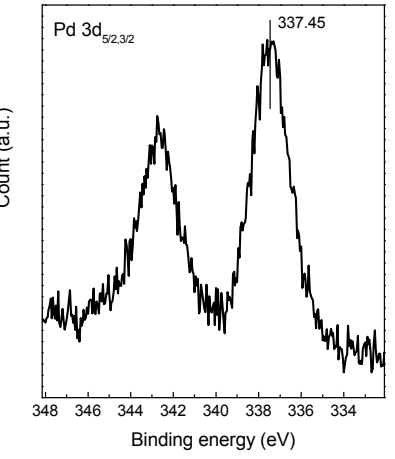

6

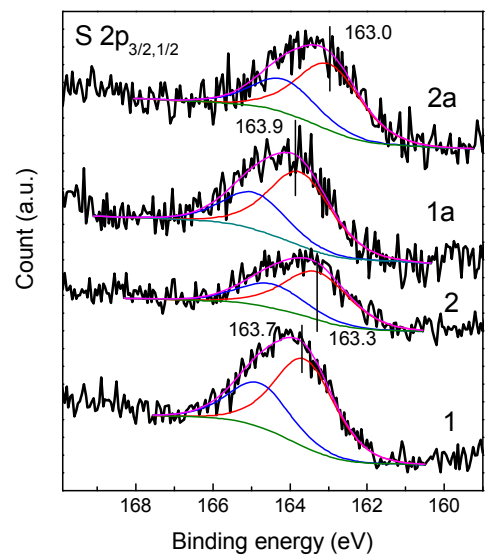

B

Рис. 10. Спектры РФЭС: а - общий спектр; б - спектр Pd; в - спектр S; 1 - образец «М5М», исходный материал; 2 - после сорбции палладия «M5M_Pd»; 1a, 2a - «M5M_Pd_Ar (5мин)»; 2b - «M5M_Pd_ $\operatorname{Ar}(10$ мин)»

для S2p остаётся достаточно высокой. Линии кислорода и кремния смещаются к более низким энергиям, возможно, из-за переноса электронной плотности с комплексов $\mathrm{Pd}$ на поверхности. Энергия связи $\mathrm{Pd} 3 \mathrm{~d}_{5 / 2}$ (рис. 10б), равная 337,5 эВ, ближе всего к хлориду $\mathrm{Pd}(\mathrm{II})$, однако атомное отношение $\mathrm{Pd} / \mathrm{Cl}$ близко к 1 , а после ионного травления - даже к 2. Отношение $\mathrm{Pd} / \mathrm{S}$ также близко к 1, но после ионного травления снижается. Относительные поверхностные концентрации палладия в результате ионного травления несколько возрастают (табл. 2). Возможно, это связано с углублением в поры материала, где происходит непосредственная сорбция металла.

Колебания в соотношении $\mathrm{Pd} / \mathrm{S}$, вероятно, вызваны различным содержанием привитой серы в сорбентах. Таким образом, в зависимости от концентрации привитых групп сорбента взаимодействие палладия(II) с поверхностью меркаптопропильного сорбента можно представить следующим образом [18]: 


$$
\begin{aligned}
& \equiv \mathrm{Si}\left(\mathrm{CH}_{2}\right)_{3} \mathrm{SH}+\left[\mathrm{PdCl}_{4}\right]^{2-} \Leftrightarrow\left[\equiv \mathrm{Si}\left(\mathrm{CH}_{2}\right)_{3} \mathrm{SPd}\right] \mathrm{Cl}+3 \mathrm{Cl}^{-}+\mathrm{H}^{+}(\mathrm{Pd}: \mathrm{S}=1: 1) \\
& 2 \equiv \mathrm{Si}\left(\mathrm{CH}_{2}\right)_{3} \mathrm{SH}+\left[\mathrm{PdCl}_{4}\right]^{2-} \Leftrightarrow\left[\equiv \mathrm{Si}\left(\mathrm{CH}_{2}\right)_{3} \mathrm{~S}\right]_{2} \mathrm{Pd}+4 \mathrm{Cl}^{-}+2 \mathrm{H}^{+}(\mathrm{Pd}: \mathrm{S}=1: 2) .
\end{aligned}
$$

Десорбция палладия (II) из сорбентов. Экспериментально достигнутая десорбция палладия(II) из ММС составляет 70-90 \% (табл. 3). Однако имеются сведения о том, что при нагревании сорбента с тиомочевиной можно извлечь из сорбента до 100 \% палладия [19].

\section{Заключение}

В работе были синтезированы мезопористые сорбенты с тиольными функциональными группами. Мезоструктурированные материалы MCM-41 и SBA-15 обладают высокой степенью гексагональной упорядоченности до и после функционализации. Сорбционная ёмкость по $\mathrm{Pd}(\mathrm{II})$ сопоставима с плотностью прививки функциональных групп. Тиольные сорбенты эффективно извлекают ионы палладия(II) из водных растворов. Максимальная сорбционная ёмкость по $\mathrm{Pd}(\mathrm{II})$ зафиксирована в интервале 1,5-1,7 ммоль/г. Скорость сорбции $\mathrm{Pd}(\mathrm{II})$ из солянокислых растворов достаточно высока, равновесие наступает в течение 2-5 мин. Вакуумное импрегнирование раствора в процессе сорбции приводит к увеличению сорбционной ёмкости на $20 \%$. Экспериментально установленная степень десорбции палладия(II) из тиольных сорбентов составляет 70-80 \% в условиях комнатной температуры.

Работа выполнена при финансовой поддержке Российского фонда фундаментальных исследований (проект № 14-03-31630).

Таблица 2. Концентрации элементов на поверхности (ат. \%.), полученные из обзорных спектров РФЭС до и после травления ионами $\mathrm{Ar}^{+}$

\begin{tabular}{|c|l|c|c|c|c|c|c|}
\hline № & \multicolumn{1}{|c|}{ Образец } & $\mathrm{C}$ & $\mathrm{O}$ & $\mathrm{Si}$ & $\mathrm{S}$ & $\mathrm{Pd}$ & $\mathrm{Cl}$ \\
\hline 1 & M5M & 11,3 & 44,8 & 21,6 & 1,3 & - & - \\
\hline 2 & M5M_Ar & 11,3 & 44,8 & 21,6 & 1,3 & - & - \\
\hline 3 & M5M_Pd & 25,5 & 49,4 & 19,4 & 1,7 & 1,5 & 1,6 \\
\hline 4 & M5M_Pd_Ar (5 мин) & 25,4 & 44,9 & 24,2 & 1,4 & 1,9 & 1,1 \\
\hline 5 & M5M_Pd_Ar (10 мин) & 25,5 & 44,2 & 24,9 & 1,0 & 2,3 & 1,1 \\
\hline
\end{tabular}

Таблица 3. Значения степени десорбции палладия(II) из МMC

\begin{tabular}{|c|c|}
\hline Сорбент & Десорбция, \% \\
\hline M2M & 76 \\
\hline M3S & 88 \\
\hline M4M & 85 \\
\hline M5M & 73 \\
\hline
\end{tabular}




\section{Список литературы}

[1] Beck J.S., Vartuli J.C., Roth W.J. et al. // J. Am. Chem. Soc. 1992. Vol. 114. P. 10834.

[2] Beck J.S., Chu C.T.-W., Johnson I.D. et.al. Pat. WO 91/11390 USA / 1991.

[3] Kozlova S.A., Zaitseva Yu. N., Kirik S.D. // Glass Physics and Chemistry. 2014. Vol. 40. № 1. P. 60-68.

[4] Kang T., Park Y., Yi J. // Ind. Eng. Chem. Res. 2004. Vol. 43. P. 1478-1484.

[5] Posada J.A., Cardona C.A., Giraldo O. // Materials Chemistry and Physics. 2010. Vol. 121. P. 215-222.

[6] Talanova G.G., Zhong L., Kravchenko O.V. et.al. // J. Applied Polymer Science. 2001. Vol. 80. P. 207.

[7] Zhang C., Li X., Pang J. // J. Applied Polymer Science. 2001. Vol. 82. P. 1587.

[8] Белоусов О.В., Парфёнов В.А., Соловьёв Л.А., Кирик С.Д. Пат. 2287485 РФ (2005) / Б. И. 2006. № 32 .

[9] Zhao D., Huo Q., Feng J. et.al. // Am. Chem. Soc. 1998. № 120. P. 6024.

[10] Гинзбург С.И. Аналитическая химия. М.: Наука, 1972. 613 с.

[11] Tura C. // Chem. Mater. 2005. V. 17. P.573-579.

[12] Brieler F.J. Grundmann P., Froba M. et al. // Chem Mater. 2005. V. 17. P. 795-803.

[13] Химия привитых поверхностных соединений / ред. Г.В. Лисичкин. М.: Физматлит, 2003. $592 \mathrm{c}$.

[14] Groen J.C., Peffer L.A.A., Pérez-Ramírez J. // Micropor. Mesopor. Mater. 2003. V. 60. P. 1-17.

[15] Kondrashova N., Saenko E., Lebedeva I. et.al. // Micropor. Mesopor. Mater. 2012. V. 153. P. 275-281.

[16] Kozlova S.A., Kirik S.D. // Micropor. Mesop. Mater. 2010. Vol. 133. P. 124-133.

[17] Walcarius A., Mercier L. // J. Mater. Chem. 2010. Vol. 20. P. 4478.

[18] Зуб Ю.Л. Автореф. дис. ... д-ра хим. наук. Харьков, 2010. 40 с.

[19] Losev V.N., Kudrina Yu.V., Maznyak N.V., Trofimchuk A.K. // J. Analytical Chemistry. 2003. Vol. 58. № 2. P. 124. 